\title{
Molybdenum Target X-Ray Features and Estrogen Receptor, Progesterone Receptor, and Human Epidermal Growth Factor Receptor 2 in Invasive Breast Cancer
}

\author{
Gulijire Tailaiti \\ Gulanbaier Maimaiti \\ Youlituzi Aikeremu \\ Batuer Tuerdi \\ Department of Radiology, People's \\ Hospital of Xinjiang Uygur Autonomous \\ Region, Urumqi, 830000, Xinjiang, \\ People's Republic of China
}

\begin{abstract}
Objective: The aim of this study was to investigate the correlations between molybdenum target X-ray mammography features and the expressions of estrogen receptor (ER), progesterone receptor (PR), and human epidermal growth factor receptor 2 (HER2) in invasive breast cancer (IBC) and their clinical significance.
\end{abstract}

Methods: The correlations between the mammographic features and expressions of ER, PR, and HER2 in 378 cases of IBC confirmed by pathology were analyzed retrospectively.

Results: The differences in the ER, PR, and HER2 positive expression between gland types were statistically significant $(\mathrm{P}<0.05)$. The expression of ER was positively correlated with the presence of nipple depression $(\mathrm{P}<0.05)$. Moreover, ER and $\mathrm{PR}$ expressions were positively correlated with the absence of axillary lymph node enlargement $(\mathrm{P}<0.05)$ and negatively correlated with the maximum tumor diameter $(\mathrm{P}<0.05)$.

Conclusion: The mammographic features of IBC are correlated with the expression of immunity indices ER, PR, and HER2 and reflect several pathological features.

Keywords: invasive breast cancer, molybdenum target X-ray mammography, estrogen receptor, progesterone receptor, human epidermal growth factor receptor 2

\section{Introduction}

Alongside societal and economic development and changes in the environment and pace of life, the incidence of breast diseases is increasing year by year, endangering women's health. According to the latest global cancer data released by the International Agency for Research on Cancer of the World Health Organization, the number of new breast cancer cases has increased to 2.26 million, surpassing the number of new lung cancer cases (2.21 million) for the first time, with breast cancer becoming the world's number one cancer. ${ }^{1}$ The etiology and progression of breast cancer have yet to be fully elucidated, but numerous studies have revealed factors involved in the occurrence of the disease, including estrogen and progesterone overstimulation, family history, and gene mutations. Developments in molecular biology have identified that estrogen receptor (ER), progesterone receptor (PR), and human epidermal growth factor receptor 2 (HER2) affect the biological behavior of a tumor and determine the tumor growth mode, morphological characteristics, prognosis, and sensitivity to clinical biologically targeted therapy and comprehensive chemotherapy. ${ }^{2,3}$ Molybdenum target X-ray mammography plays an important
Correspondence: Batuer Tuerdi Department of Radiology, People's Hospital of Xinjiang Uygur Autonomous Region, 91 Tian Chi Road, Urumqi, 830000, Xinjiang,

People's Republic of China

Tel +86099l 8564664

Email batuer859@I63.com 
role in the early detection, diagnosis, and prognostic evaluation of breast lesions, enabling lesion diagnosis based on its ability to determine lesion morphology and calcification. ${ }^{4}$ This study explores the correlation of the mammographic features of invasive breast cancer (IBC) with the expression of immunity indices ER, PR, and HER2 to indirectly identify the biological behavior of tumors through X-ray mammography findings and provide valuable imaging reference information for preoperative adjuvant endocrine therapy and the prognostic evaluation of breast cancer.

\section{Information and Methods General Information}

The data of 378 IBC patients who underwent preoperative $\mathrm{X}$-ray mammography (with confirmation by surgery and pathology) in the Xinjiang Uygur Autonomous Region from January 2015 to December 2019 were retrospectively analyzed. The images were read and reported on by two senior imaging physicians. The patients were aged between 25 and 86 years, with an average age of $53.2 \pm$ 12.0 years.

The patient inclusion criteria were (1) that they met the diagnostic criteria for IBC; ${ }^{5}$ (2) that they had undergone breast X-ray mammography and had surgically and pathologically confirmed invasive ductal breast carcinoma; (3) that complete clinical and molybdenum target X-ray mammography data were available; and (4) that they had provided signed informed consent.

The exclusion criteria ruled out (1) patients who had not undergone surgery; (2) male patients; (3) patients with non-IBC pathology; (4) patients who had received radiotherapy, chemotherapy, or endocrine-targeted therapy before the examination; and (5) special populations, such as pregnant or lactating patients and those with malignant tumors other than IBC.

\section{Detection Methods}

All patients were routinely photographed using a Senographe 2000D full-field digital mammography camera (GE, USA) from the bilateral craniocaudal (CC) view and mediolateral oblique view. In special circumstances, certain supplementary positions were adopted, eg, the mediolateral view, medial CC (MCC) view, and lateral CC (LCC) view, and local compression and magnification were also performed if necessary.

\section{Image Analysis}

The molybdenum target X-ray films were stored in a Great Wall PACS workstation and read in a double-blind process. In line with the Breast Imaging Reporting and Data System proposed and recommended by the American College of Radiology, ${ }^{6}$ the reading of the X-ray imaging results was carried out by two senior imaging specialists. They read the films and, for each patient, carefully observed and recorded the most common X-ray features (mass and calcification, mass without calcification, no mass with calcification, or no mass or calcification), the lesion location (outer upper quadrant, outer lower quadrant, inner lower quadrant, inner upper quadrant, or central area), the breast gland type (non-dense or dense), whether the nipple was depressed, the largest diameter of the lesion, whether the axillary lymph nodes were enlarged, and whether the areola and surrounding skin were thickened. When there was diagnostic disagreement, they asked another imaging professional above the sub-high level to diagnose the case and resolve it with them.

\section{ER, PR, and HER2 Expression Detection Method}

The immunohistochemical streptavidin-peroxidase (SP) method was used to select breast cancer tissue that was punctured or resected during surgery. According to the guidelines, two pathologists independently read the radiographs in a double-blind manner to observe the ER, PR, and HER2 expression. The positive ER and PR staining was localized in the nucleus, showing brown particles. The positive HER2 staining was localized in the cytoplasm or cell membrane and appeared as brown granules. The ER and PR receptor expression criteria were positive, negative, or undecipherable. (1) Positive: The proportion of tumor cells with positive staining in the whole section to all tumor cells was evaluated. When $\geq 1 \%$ of tumor nuclei showed different degrees of staining, this was considered positive. (2) Negative: Approximately $<1 \%$ of the tumor nuclei in the whole section showed varying degrees of staining or no staining at all. Negative results had to be determined on the basis of good staining of internal and external controls. In the case of ER-/PR+, repeated ER and PR tests were needed to exclude ER false-negative or PR false-positive cases.

In the HER2 test procedure, breast cancer specimens could usually be tested by Immunohistochemistry (IHC) first. HER2 positive for IHC $3+$ and HER2 negative for IHC 0 and $1+$. IHC $2+$ the further use of the method of 
Table I Correlation Between Common Signs of Molybdenum Target X-Ray Mammography and the Expressions of ER, PR and HER-2

\begin{tabular}{|c|c|c|c|c|c|c|c|c|c|c|}
\hline \multirow[t]{2}{*}{ Mammographic Features } & \multirow[t]{2}{*}{ Cases } & \multicolumn{2}{|c|}{$\begin{array}{c}\text { Positive } \\
\text { Expressions of ER }\end{array}$} & \multirow[t]{2}{*}{ P value } & \multicolumn{2}{|c|}{$\begin{array}{c}\text { Positive } \\
\text { Expressions of PR }\end{array}$} & \multirow[t]{2}{*}{$P$ value } & \multicolumn{2}{|c|}{$\begin{array}{c}\text { Positive } \\
\text { Expressions of } \\
\text { Her-2 }\end{array}$} & \multirow[t]{2}{*}{$P$ value } \\
\hline & & No & Yes & & No & Yes & & No & Yes & \\
\hline Mass with calcification & 206 & 61 & 145 & 0.158 & 105 & 101 & 0.346 & 109 & 97 & $0.04 I$ \\
\hline Mass without calcification & 135 & 54 & 81 & & 64 & 71 & & 83 & 52 & \\
\hline No mass with calcification & 23 & 9 & 14 & & 13 & 10 & & 7 & 16 & \\
\hline No mass no calcification & 14 & 3 & II & & 4 & 10 & & 8 & 6 & \\
\hline$X^{2}$ value & & & & 5.192 & & & 3.309 & & & 8.271 \\
\hline
\end{tabular}

in situ hybridization (FISH) for HER2 gene amplification state detection and can also select different organizations piece to test or send other lab for testing. If the IHC appeared to be inconsistent with the results of the in situ hybridization detection of the cases, multidisciplinary discussion was suggested, the reason was analyzed, and corresponding treatment strategies were formulated.

\section{Statistical Analysis}

The data were analyzed using the statistical software SPSS 23.0. The count data were evaluated using a chi-square $\left(\mathrm{X}^{2}\right)$ test or Fisher's exact probability test. The measurement data were evaluated using a Spearman's rank correlation test. A P-value $<0.05$ was considered statistically significant.

\section{Results}

\section{Molybdenum Target X-Ray Features of IBC}

Of the 378 patients enrolled in this study, 241 (63.77\%) presented with tumor mass, 140 (37.04\%) with nipple depression, $160(42.33 \%)$ with thickening of the areola and surrounding skin, and 141 (37.3\%) with axillary lymph node enlargement. The lesion was located in the outer upper quadrant in 179 patients $(47.35 \%)$, in the outer lower quadrant in 25 patients $(6.61 \%)$, in the inner lower quadrant in 25 patients $(6.61 \%)$, in the inner upper quadrant in 58 patients (15.34\%), and in the central area in 91 patients (24.07\%).

\section{Correlation Between Molybdenum Target X-Ray Features and ER, PR, and HER2 Expression in IBC}

The positive expression rates of the immunity indices for the 378 patients were as follows: ER, 50.79\% (192/378); PR,
$66.40 \%(251 / 378)$; and HER2, $45.50 \%$ (172/378). There was no significant difference in the ER and PR expression between the most common molybdenum target X-ray features of IBC $(\mathrm{P}>0.05$, Table 1). The positive expression of HER2 was positively correlated with calcification and absence of mass $(P<0.05$, Table 1). The differences in the ER, PR, and HER2 positive expression between the gland types were statistically significant $(\mathrm{P}<0.05$, Table 2$)$, and the ER expression was positively correlated with the presence of nipple depression ( $\mathrm{P}<0.05$, Table 2). Moreover, there were statistically significant differences in the positive expression of ER, PR, and HER2 between the presence and absence of thickening of the areola and surrounding skin as well as between the lesion sites ( $P>0.05$, Table 2$)$. The ER and PR expressions were positively correlated with the absence of axillary lymph node enlargement $(\mathrm{P}<0.05$, Table 2) but negatively correlated with the maximum tumor diameter $(\mathrm{P}<0.05$, Table 2$)$.

\section{Correlation Between ER, PR, and HER2 Expressions in Invasive Ductal Breast Carcinoma}

There was a positive correlation between the expressions of ER and $P R\left(X^{2}=146.182, P<0.001\right)$ and negative correlation between the expressions of ER and HER2 $\left(\mathrm{X}^{2}=10.130, \mathrm{P}=\right.$ $0.001)$ and PR and HER2 $\left(X^{2}=7.063, P=0.008\right.$, Table 3$)$.

\section{Discussion}

Breast cancer has become the most prevalent cancer endangering the health of women in China. Among the different pathological types of breast cancer, invasive ductal carcinoma is the most common. ${ }^{7}$ The morphological characteristics of breast cancer are often related to 
Table 2 Correlation Between Other Signs of Molybdenum Target X-Ray Mammography and the Expressions of ER, PR and HER-2

\begin{tabular}{|c|c|c|c|c|c|c|c|c|c|c|}
\hline \multirow[t]{2}{*}{ Mammographic Features } & \multirow[t]{2}{*}{ Cases } & \multicolumn{2}{|c|}{$\begin{array}{c}\text { Positive } \\
\text { Expressions } \\
\text { of ER }\end{array}$} & \multirow[t]{2}{*}{$P$ value } & \multicolumn{2}{|c|}{$\begin{array}{c}\text { Positive } \\
\text { Expressions } \\
\text { of PR }\end{array}$} & \multirow[t]{2}{*}{$P$ value } & \multicolumn{2}{|c|}{$\begin{array}{c}\text { Positive } \\
\text { Expressions } \\
\text { of Her-2 }\end{array}$} & \multirow[t]{2}{*}{$P$ value } \\
\hline & & No & Yes & & No & Yes & & No & Yes & \\
\hline Gland type & & & & 0.008 & & & 0.032 & & & 0.030 \\
\hline Non-dense type & 200 & 55 & 145 & & 88 & 112 & & 120 & 80 & \\
\hline Dense type & 178 & 72 & 106 & & 98 & 80 & & 87 & 91 & \\
\hline Whether the nipples are depressed & & & & 0.013 & & & 0.407 & & & 0.433 \\
\hline No & 238 & 91 & 147 & & 121 & 117 & & 134 & 104 & \\
\hline Yes & 140 & 36 & 104 & & 65 & 75 & & 73 & 67 & \\
\hline Whether the skin and areola are thickened & & & & 0.136 & & & 0.719 & & & 0.584 \\
\hline No & 218 & 80 & 138 & & 109 & 109 & & 122 & 96 & \\
\hline Yes & 160 & 47 & 113 & & 77 & 83 & & 85 & 75 & \\
\hline Whether axillary lymph nodes are swollen & & & & 0.017 & & & 0.013 & & & 0.552 \\
\hline No & 237 & 69 & 168 & & 105 & 132 & & 127 & 110 & \\
\hline Yes & $|4|$ & 58 & 83 & & 81 & 60 & & 80 & 61 & \\
\hline Lesion sites & & & & 0.218 & & & 0.287 & & & 0.704 \\
\hline Upper outer quadrant & 179 & 68 & 111 & & 90 & 89 & & 98 & 81 & \\
\hline Lower outer quadrant & 25 & 6 & 19 & & 13 & 12 & & 11 & 14 & \\
\hline Lower inner quadrant & 25 & 11 & 14 & & 14 & 11 & & 14 & 11 & \\
\hline Upper inner quadrant & 58 & 16 & 42 & & 21 & 37 & & 30 & 28 & \\
\hline Central area & 91 & 26 & 65 & & 48 & 43 & & 54 & 37 & \\
\hline
\end{tabular}

Table 3 Correlation Between Lesion Sites in Molybdenum Target X-Ray Mammography and the Expressions of ER, PR and HER-2

\begin{tabular}{|c|c|c|c|c|c|c|c|}
\hline \multirow[t]{2}{*}{ Mammographic Features } & \multirow[t]{2}{*}{ Cases } & \multicolumn{2}{|c|}{ Positive Expressions of ER } & \multicolumn{2}{|c|}{ Positive Expressions of PR } & \multicolumn{2}{|c|}{ Positive Expressions of Her-2 } \\
\hline & & No & Yes & No & Yes & No & Yes \\
\hline \multicolumn{8}{|l|}{ Maximum lesion diameter } \\
\hline$>5 \mathrm{~cm}$ & 21 & 12 & 9 & 15 & 6 & 10 & II \\
\hline$>2 \sim \leqq 5 \mathrm{~cm}$ & 176 & 66 & 110 & 94 & 82 & 95 & 81 \\
\hline$\leqq 2 \mathrm{~cm}$ & 181 & 49 & 132 & 77 & 104 & 102 & 79 \\
\hline$r$ & \multicolumn{3}{|c|}{-0.150} & \multicolumn{2}{|c|}{-0.143} & \multicolumn{2}{|c|}{0.036} \\
\hline$P$ value & \multicolumn{3}{|c|}{0.003} & \multicolumn{2}{|c|}{0.005} & \multicolumn{2}{|c|}{0.482} \\
\hline
\end{tabular}

tumor invasion. Molybdenum target X-ray mammography is sensitive in the detection of microcalcification in the breast and has become the primary imaging examination method for the early diagnosis of breast cancer, especially breast cancer with microcalcification as the only characteristic. Molybdenum target X-ray features are closely related to the prognosis, ${ }^{8}$ and the X-ray signs of breast cancer are closely related to the pathology. With developments in immunohistochemistry and molecular biotechnology, it has been found that the molecular biological indicators related to breast cancer, eg, ER, PR, and HER2, determine the biological activity of a tumor and the imaging findings. Different pathological changes produce different tumor growth modes, morphological changes, and X-ray manifestations. Therefore, examining the correlation between imaging features and molecular biological indicators related to breast cancer can provide a reliable basis for the evaluation, prognosis, and endocrine- and molecular-targeted therapy of breast cancer. 
The most common molybdenum target X-ray features of IBC include mass and calcification. ${ }^{9}$ In this study, these signs were divided into four groups, ie, mass and calcification, no mass with calcification, mass without calcification, and no mass or calcification, to explore the correlations between ER, PR, and HER2 expression. In normal mammary epithelial cells, ER and PR regulate growth and development by regulating the target organ, the mammary gland. The occurrence and progression of breast cancer are closely related to hormone expression. This study found no significant difference in the ER and PR positive expression between the most common molybdenum target X-ray features of IBC $(\mathrm{P}>0.05)$. The may be because when ER and PR disappear in cancer cells (ie, negative ER and PR expression), the proliferation of the cancer cells is no longer regulated by endocrine hormones. Such tumors are poorly differentiated and have a poor prognosis; they often display the morphology of typical infiltrative growth, such as mass and calcification. ${ }^{10}$ However, this study did find significant differences in the HER2 expression between the most common molybdenum target X-ray features of IBC $(\mathrm{P}<0.05)$. The positive expression rate of HER2 was highest in patients with calcification without mass, consistent with previous results reported in China and other countries. ${ }^{11,12}$ One such study demonstrated that the expression of HER2 is correlated with the histological type and differentiation degree of breast cancer: ${ }^{13}$ HER2 overexpression often indicates poor prognosis in patients with breast cancer. It is therefore speculated that breast cancer with calcification without mass is more invasive and malignant than that with other features and has a poor prognosis.

This study found statistically significant differences in the ER, PR, and HER2 expressions between the gland types $(\mathrm{P}<0.05)$. The positive expression rates of ER and PR were highest in the non-dense gland type, for which the negative expression rate of HER2 was highest. A previous study found that gland density on molybdenum target X-ray imaging is highly negatively correlated with ER and PR expression - the lower the ER and PR expression, the higher the gland density. ${ }^{14}$

There was a significant difference in the ER expression between the presence and absence of nipple depression $(\mathrm{P}<$ 0.05). The positive expression of ER was positively correlated with nipple depression, ie, its positive expression rate was highest in patients with nipple depression. This may be because the 63 patients over 55 years of age who showed signs of inverted nipples, 113 of whom (77.93\%) were positive for ER; with age, the nipple becomes depressed due to mammary duct shortening and tissue fibrosis contracture. Deeper analysis is needed to obtain more conclusive results.

In addition, the thickening of the areola and surrounding skin and the lesion location are often associated with local or lymph node metastasis of breast cancer. ${ }^{14-16}$ The former is a sign of breast cancer infiltration on mammography. Generally, the skin in the areola on molybdenum target mammography is slightly thicker at $1 \sim 5 \mathrm{~mm}$, which is $0.3 \sim 0.5 \mathrm{~mm}$ thicker than the skin in other places. The thickness of the skin can be measured on molybdenum target mammography. If the skin thickness in the areola is over $5 \mathrm{~mm}$, the areola is considered to be thickened. Breast cancer easily invades fibrous tissue, which may cause thickening of the areola and surrounding skin; therefore, it can be regarded as an important signal of tumor invasion and development to the middle and late stages. The lesion location is also an important factor affecting the recurrence and metastasis of breast cancer and overall survival. ${ }^{17}$ This study found that there were statistically significant differences in the ER, PR, and HER2 expressions between the presence and absence of thickening of the areola and surrounding skin as well as between the lesion sites $(\mathrm{P}>$ $0.05)$. This may be related to the different receptor expressions between primary and metastatic lesions and even between different metastatic lesions. ${ }^{18}$

Axillary lymph node enlargement in molybdenum target $\mathrm{X}$-ray mammography refers to the increase of the short-axis diameter of axillary lymph nodes such that the ratio of the long- to short-axis diameter is lower than two in each group. ${ }^{19}$ The axillary lymph node is the most common metastatic site of breast cancer, and axillary lymph node enlargement often indicates that breast cancer is infiltrating and invading the nodes. This study found significant differences in the ER and PR expression between the presence and absence of axillary lymph node enlargement $(\mathrm{P}<0.05)$. The positive expression rates of ER and PR were highest in patients without axillary lymph node enlargement, consistent with the fact that high ER and PR expression rates indicate a longer survival time. ${ }^{20}$

Lesion size is an important indicator in the tumornode-metastasis staging of breast cancer. The larger the diameter, the greater the chance of metastasis to and invasion of surrounding areas and the higher the degree of malignancy. ${ }^{21}$ In this study, the positive expression rates of ER and PR were highest when the maximum lesion diameter was $\leq 2 \mathrm{~cm}$, and their expression was negatively correlated with the maximum lesion diameter $(\mathrm{P}<0.05)$. This suggests that lower expression of ER and PR in IBC 
is associated with poor differentiation, rapid growth, and low synthesis of the hormone receptor of tumors.

For the 378 patients in this study, the positive expression rate of ER was $50.79 \%(192 / 378)$, that of PR was $66.40 \%$ (251/378), and that of HER2 was $45.50 \%$ (172/ 378). There was a positive correlation between the expressions of ER and PR $\left(\mathrm{X}^{2}=146.182, \mathrm{P}<0.001\right)$, ie, the positive expression rate of ER was highest in cells with positive expression of PR (95.31\%). However, there was a negative correlation between the expressions of ER and HER2 $\left(\mathrm{X}^{2}=10.130, \mathrm{P}=0.001\right)$, ie, the positive expression rate of ER was highest in cells with negative expression of HER2 $(60.56 \%)$. There was also a negative correlation between the expressions of PR and HER2 $\left(\mathrm{X}^{2}\right.$ $=7.063, \mathrm{P}=0.008)$, ie, the positive expression rate of PR was highest in cells with negative expression of HER2 (61.46\%). The results revealed that ER has a synergistic effect with PR and an antagonistic effect with HER2 in the growth and development of IBC.

Our limitations included a small sample size and the possible need to verify the results via more methods such as rhodium.

In summary, the features of molybdenum target X-ray mammography of IBC are correlated with the expressions of immunity indices ER, PR, and HER2 and reflect several pathological features. The expressions of ER, PR, and HER2 are both interrelated and unique.

\section{Ethics Approval and Consent to Participate}

This study was conducted with approval from the Ethics Committee of People's Hospital of Xinjiang Uygur Autonomous Region. This study was conducted in accordance with the declaration of Helsinki. Written informed consent was obtained from all participants.

\section{Acknowledgments}

We would like to acknowledge the hard and dedicated work of all the staff that implemented the intervention and evaluation components of the study.

\section{Funding}

There is no funding to report.

\section{Disclosure}

The authors declare that they have no competing interests.

\section{References}

1. Liu JL. Breast cancer is the most common cancer worldwide for the first time. Chin J Breast Dis. 2020;14(06):389.

2. Lialiaris TS, Kouskoukis A, Georgiou G, et al. Expression of 6 common antigenic markers in invasive ductal breast carcinoma: potential clinical implications. Appl Immunohistochem Mol Morphol. 2011;19(2):106-111. doi:10.1097/PAI.0b013e3181e181b1

3. Yan J, Liu XL, Han LZ, et al. Relation between Ki-67, ER, PR, Her2/ neu, p21, EGFR, and TOP II- $\alpha$ expression in invasive ductal breast cancer patients and correlations with prognosis. Asian Pac J Cancer Prev. 2015;16(2):823-829. doi:10.7314/APJCP.2015.16.2.823

4. Hu C, Liu J, Zhao Y, Liu P. Study on the relationship of tumor projection position and body surface positioning by mammography conventional position. J Pract Radiol. 2013;29(10):1662-1665.

5. Breast Cancer Professional Committee of Chinese Anti-Cancer Association. Chinese anti-cancer association guidelines and specifications for diagnosis and treatment of breast cancer (2019 edition). Chin Oncol. 2019;29(08):609-680.

6. Magny SJ, Shikhman R, Keppke AL. Breast, imaging, reporting and data system (BI RADS). In: StatPearls. Treasure Island (FL): StatPearls Publishing; 2020.

7. DeSantis C, Ma J, Bryan L, Jemal A. Breast cancer statistics, 2013. CA Cancer J Clin. 2014;64(1):52-62. doi:10.3322/caac.21203

8. Zhai C, Zheng J, Peng W. Advances in imaging studies of triple-negative breast cancer. Mod Pract Med. 2018;30(05):565-567.

9. Rong X, Kang Y, Wu Z, Zhang L, Gu T, Wu Y. Comparison of full digital X-ray findings and clinicopathological features of breast cancer in the elderly and young people. Chin J Gerontol. 2018;38 (07):1664-1665.

10. Hwang SH, Park DJ, Jee YS, et al. Risk factors for operative complications in elderly patients during laparoscopy-assisted gastrectomy. J Am Coll Surg. 2009;208(2):186-192. doi:10.1016/j. jamcollsurg.2008.10.023

11. Liu X, Lin Q, Cui C, Jiang Z, Bian T. Correlation analysis of HER-2 and mammographic features of breast cancers with ER and PR in the same expression condition. J Clin Radiol. 2015;34(1):31-35.

12. Ivkovic-Kapicl T, Knezevic-Usaj S, Djilas-Ivanovic D, Panjkovic M. Correlation of HER-2/neu protein overexpression with other prognostic and predictive factors in invasive ductal breast cancer. In Vivo (Brooklyn). 2007;21(4):673-678.

13. Park H, Chang SK, Kim JY, Lee BM, Shin HS. Risk factors for distant metastasis as a primary site of treatment failure in early-stage breast cancer. Chonnam Med J. 2014;50(3):96-101. doi:10.4068/ cmj.2014.50.3.96

14. Eriksson L, Czene K, Rosenberg L, Humphreys K, Hall P. Possible influence of mammographic density on local and locoregional recurrence of breast cancer. Breast Cancer Res. 2013;15(4):R56. doi: $10.1186 /$ bcr3450

15. Wang Y, Chen Z, Zhang D, Zhou H, Cao X, Wang X, Effect of the primary tumor location on the prognosis of breast invasive ductal carcinoma patients treated with radical mastectomy. Chin J Oncol. 2019;(09):686-692. doi:10.3760/cma.j.issn.0253-3766.2019.09.008

16. Zhuang L, Wang H, Song F, Wang X. The diagnostic value of high frequency ultrasonography and molybdenum target imaging for early breast cancer. J Pract Radiol. 2017;33(007):1020-1023.

17. Lim ST, Choi JE, Kim SJ, et al. Prognostic implication of the tumor location according to molecular subtypes in axillary lymph node-positive invasive ductal cancer in a Korean population. Breast Cancer Res Treat. 2016;156(3):473-483. doi:10.1007/s10549-0163771-6

18. Sun L, Yu DH, Sun SY, Zhuo SC, Cao SS, Wei L. Expressions of ER, PR, HER-2, COX-2, and VEGF in primary and relapsed/metastatic breast cancers. Cell Biochem Biophys. 2014;68(3):511-516. doi:10.1007/s12013-013-9729-y 
19. Guan X, Yu L, Deng Q, Lin Y, Luo B. Correlation analysis of breast cancer contrast-enhanced ultrasound and its prognostic factors. Chin J Ultrasound Med. 2016;32(12):1069-1072.

20. Itoh M, Iwamoto T, Matsuoka J, et al. Estrogen receptor (ER) mRNA expression and molecular subtype distribution in ER-negative/progesterone receptor-positive breast cancers. Breast Cancer Res Treat. 2014;143(2):403-409. doi:10.1007/s10549-013-2763-Z
21. Smeets A, Ryckx A, Belmans A, et al. Impact of tumor chronology and tumor biology on lymph node metastasis in breast cancer Springerplus. 2013;23(2):480. doi:10.1186/2193-1801-2-480

\section{Publish your work in this journal}

The International Journal of General Medicine is an international, peer-reviewed open-access journal that focuses on general and internal medicine, pathogenesis, epidemiology, diagnosis, monitoring and treatment protocols. The journal is characterized by the rapid reporting of reviews, original research and clinical studies across all disease areas. The manuscript management system is completely online and includes a very quick and fair peer-review system, which is all easy to use. Visit http://www.dovepress.com/ testimonials.php to read real quotes from published authors.

Submit your manuscript here: https://www.dovepress.com/international-journal-of-general-medicine-journal 